(C2019, Elsevier. Licensed under the Creative Commons Attribution-NonCommercialNoDerivatives 4.0 International http://creativecommons.org/about/downloads 


\title{
Planning for an uncertain future: the challenges of a locally based collaborative approach to coastal development decisions.
}

\author{
Dr Tracey Coates ${ }^{a}$ and Sue Tapsell ${ }^{b}$ \\ ${ }^{a}$ Kingston University, London, United Kingdom. (Corresponding author) \\ ${ }^{b}$ Formerly of Flood Hazard Research Centre, Middlesex University, United Kingdom.
}

\begin{abstract}
In England spatial planning decisions regards allowing development in coastal areas at risk of flooding or erosion are largely devolved to negotiations at what is said to be the local scale. Such development is discouraged but may be allowed as long as it is possible to demonstrate wider sustainability benefits said to outweigh the risk. It is at this point a range of stakeholders, representing different organisations and concerns must come together to try and resolve the tension between new development and risk reduction. Participants must navigate an evolving, complex, multiscale risk governance network to achieve an effective risk dialogue. The paper critically examines this apparently local, collaborative method, to understand the contributions and challenges of such an approach and provide suggestions to support this process. Semi structured interviews with thirty interviewees across three coastal locations in England reveal a number of key areas of contention, centred on: the risk data, local boundaries and planning timescales. In a complex system, mixing formal and informal planning spaces, stakeholders represent diverse spaces, a variety of organisational concerns and different planning horizons. At least some local concerns have a significant influence, but the system struggles to address national and strategic issues.
\end{abstract}

Key words: spatial planning, coast, flood, erosion, local, collaboration

\section{Introduction}

Spatial planning (SP), sometimes known as land use planning, is increasingly recognised as having a role to play in Flood and Coastal Erosion Risk Management (FCERM) in England (Begg, Walker and Kuhlicke 2015) following the UK government's move to more integrated risk-based approaches to managing hazards (Porter and Demeritt 2012). England is unusual in having a discretionary planning system, where development decisions are negotiated by a range of local actors. National guidance in the form of the National Planning Policy Framework (NPPF) (DCLG 2012, MCHLG 2019) discourages new building in locations identified as having higher risk to flooding or erosion but there is provision to allow development if it is deemed necessary and can show "wider sustainability benefits".

In a small crowded island such as the UK, where there is considerable pressure on space, compromises are required and spatial planning has become the primary focus of a conflict between land, water and people (Pardoe, Penning-Rowsell and Tunstall 2011). 5.2 million homes and businesses are at risk from flooding in England; 700 are at risk of coastal erosion over the next 20 years and a further 2,000 may become vulnerable over the next 50 years (EA 2018) with development continuing in areas at risk (EA 2018, Smith and Priestly 2016). Coastal areas pose specific challenges because of their particular physical, social, economic and environmental properties and their vulnerability to climate change and sea level rise.

The English planning system operates though a complex mix of formal and informal overlapping spaces which have undergone considerable alteration in recent years (Allmendinger, Haughton \& Shepherd 2016). These changes are ostensibly designed to promote local involvement and decision making but have tended to increase the number of informal arrangements leading to complex spatial interactions, particularly at the coast where marine matters and authorities must also be considered alongside land and freshwater 
management. The deliberation of development decisions at a local level, where spatial planners are accountable to a locally elected council, is said to have a democratic legitimacy (Green 2014) and be flexible enough to "take local circumstances into account, to reflect the character, needs and opportunities of each area" (MHCLG 2019:5). However, what constitutes local is less clear and accountability can be opaque.

This exploratory research critically examines this complex social-political process from multiple perspectives in a variety of contexts, during a time of considerable policy change. It explores the lived realities of how such discussions operate 'on the ground' to produce specific decisions. Understanding of stakeholders' perspectives can be used by practitioners to support reaching agreement in the process of collaborative decision making and by academics and policy makers in evaluating the effectiveness of an apparently local and democratic process. We therefore ask the following.

In a collaborative process between stakeholders representing a variety of scales and organisational concerns:

- How is local being represented and how does this shape perspectives?

- What are the factors influencing the risk communication process?

- How are planning aims being articulated?

\section{Literature}

\subsection{Spatial planning: balancing competing needs to achieve sustainable development}

Spatial planning in the English context involves bringing together strategic perspectives on land development, environmental issues, resource use, transport, economic development, social infrastructure, and other similar concerns (Allmendinger and Haughton 2007). The purpose of the planning system as set out in the guiding national document the National Planning Policy Framework (NPPF) (first published in 2012 but revised in 2018 and 2019) is "to contribute to the achievement of sustainable development" (MHCLG 2019:5). Somewhat idealistically the NPPF (MHCLG 2019:5) suggests that the three overarching objectives of sustainable development (economic, social and environmental), "need to be pursued in mutually supportive ways (so that opportunities can be taken to secure net gains across each of the different objectives)"; a statement that fails to acknowledge planning's role in attempting to reconcile "conflicting objectives and aspirations" (Allmendinger and Haughton 2012:89). As FCERM and SP have both expanded their remit, there is closer integration between the two and formal recognition within the English planning system of the need to take account of climate change, flooding and coastal change (erosion). So spatial planning encompasses a very broad range of concerns and attempts to balance competing interests in order to produce development which meets the needs of the present without compromising the ability of future generations to meet their own needs (MHCLG 2018).

The English planning system is a 'discretionary system' unlike in much of the EU which has a more rigid 'binding system'. Crucially, therefore, each decision on whether to build within areas at risk of flood or erosion is "subject to administrative and political discretion" with plans only providing "general guidance" for local planners (Albrechts 2004:744). Somewhat controversially, through the Localism Act 2011, the government abolished regional planning in England and revoked existing regional spatial strategies (RSSs). As well as leaving a strategic gap between local and national government (Allmendinger, Haughton and Shepherd 2016) this left the setting of housing targets to the local level. The NPPF then became the main document guiding spatial planning in England. These guidelines are interpreted by Local Planning Authorities (LPA), in line with local circumstances, to produce a Local Plan (LP) which in turn provides direction for individual development decisions. The process should fully involve everyone who has an interest in the document, including planners, local politicians, environmental groups/organisations, housing developers and the public. This devolved process is said to encourage a focus on local circumstances, allowing flexibility to local priorities (Pardoe, Penning-Rowsell and Tunstall 2011) whilst seeking to reconcile conflicting objectives and constraints (Green 2014). 
Negotiation is therefore a key aspect of the English SP system. The Environment Agency (EA), as the nondepartmental public body with strategic responsibility for flood and erosion risk management in England (sponsored by the Department for Environment, Food and Rural Affairs - see Fig. 1) plays a central role in these negotiations and their influence has been increasing. In 2001 they became a statutory consultee on applications for planning permission in areas at risk of flooding and in 2006 they were given additional powers to refer decisions for review by central government (Pardoe, Penning-Rowsell and Tunstall 2011). This has caused some tension with local government planners who see this as a challenge to their professional judgement by an agency with a significantly narrower mandate and which can lead to a clash of institutional priorities and cultures (Green 2014, Porter and Demeritt 2012). So, whilst the national document provides guidance, this is interpreted at the local level and there are a number of points at which decisions can be contested by interested parties.

The NPPF in 2012 set out a number of requirements relating to climate change, flooding and coastal change (DCLG 2012). Broadly speaking, these aim to avoid new development in areas at risk from flood and/or erosion. Planning is said to play a key role in "minimising vulnerability and providing resilience to the impacts of climate change" (p21). Accordingly, Local Plans "should take account of climate change over the longer term, including factors such as flood risk [and] coastal change" and new development "should be planned to avoid increased vulnerability to the range of impacts arising from climate change" (p23). Crucially, building may be allowed in flood-risk areas following the application of a sequential, risk-based approach and through an exceptions test. The sequential test suggests development "should not be allocated or permitted if there are reasonably available sites appropriate for the proposed development in areas with a lower probability of flooding" (p24). An exception may be allowed if "the development provides wider sustainability benefits to the community that outweigh flood risk" and the development is deemed "safe for its lifetime taking account of the vulnerability of its users, without increasing flood risk elsewhere" (p24). The update to the framework in 2019 adds a little more detail but the principle remains the same.

So, whilst building in areas at higher levels of risk is discouraged in the NPPF, it is still possible if wider sustainability benefits can be argued to exist. In 2016-17 over $8 \%$ of new residential development was constructed in flood risk areas and $4 \%$ of final planning decisions were not in line with EA planning advice (EA 2018). The updated NPPF places more emphasis on meeting the housing need "to support the Government's objective of significantly boosting the supply of homes" (MHCLG 2019:17) which may increase this figure. Sustainability is a term open to interpretation and it is at this point that a whole range of organisations, groups, interests and scales collide.

\subsection{Collaborative approaches to decision making}

This deliberative approach is linked to the broader movement in environmental governance, affecting both the planning profession and FCERM, where collaboration is said to lead to better decisions and more beneficial social outcomes (Challies et al. 2016). This approach has been reinforced by the influence of resilience as a policy narrative, which may be a highly contested concept with numerous arguments about its operationalisation (Welsh 2013) but it is said to be "the pervasive idiom of global governance" (Walker and Cooper 2011: 144). A wide range of actors are identified as necessary to produce resilience and stakeholder participation is seen as pivotal (Aldunce et al 2016) in a participatory and collaborative governance approach (Thaler and Levin-Keitel 2016). This would seem to support planning's long-standing role in engaging with wider actors and agencies, to enable concrete proposals to emerge through dialogue and deliberation (White and O'Hare 2014). However, resilience, like sustainability, is a term open to multiple and sometimes conflicting interpretations and so can be used to pursue a range of different goals (Tanner, Bahadur and Moench 2017). The term's flexibility may be beneficial in bringing together disparate groups (Tanner, Bahadur and Moench 2017) but it is important to understand how these terms are being deployed by those involved, at what scales and to what ends (Weichselgartner and Kelman 2014) 


\subsection{The challenges of risk communication}

Collaborative approaches require the involvement of local stakeholders from a wide range of backgrounds. However, communication and engagement are especially problematic where 'risk' is concerned, for the data used in mapping, modelling and forecasting has inherent uncertainties (EA 2018). There have been attempts to produce best practice guides but "the very idea and purposes of risk communication are contested and thus that what counts as 'good' risk communication depends very much on the standpoint from which it is judged" (Demeritt and Norbert 2014: 1). Collaborative approaches rest largely on a risk dialogue model based on two way exchange, which has high ideals but which may face a number of barriers in implementation (Demeritt and Norbert 2014). As Leiss (1996) notes, the disagreements that can arise over the best way to assess and manage risk may be based on disagreement over principles or approaches, differences in the information base available or a failure to consider the others' position sufficiently. Conveying risk and uncertainty science to professionals can be difficult, they may be reluctant to articulate the uncertainties in risk data because it may be exploited by those wishing to circumvent planning restrictions (Faulkner et al 2007). This highlights the difference between the scientific uncertainties inherent in the data and the decision-making uncertainties faced by professionals who must manage the second-order institutional risks of criticism and blame which can arise from discharging first order risk management responsibilities to protect society (Kuklicke and Demeritt 2016). Risk communication is complex and fraught with difficulties and underlying motives need to be explored.

\subsection{Localism and the problems of defining local}

The shift to more collaborative approaches runs in parallel with the move to localism, which favours the 'local' as a level where decisions should be made, and problems can be best addressed (Begg, Walker and Kuhlicke 2015: 686). The Localism Act 2011 enabled the removal of the regional tier of planning and is said to "make the planning system clearer, more democratic, and more effective" (DCLG 2011: 11). This would seem to suggest a simplified system of national guidance and local implementation. Yet what we find is a complex mix of fluid scales, intensifying the "informal, fuzzy and 'soft' spaces" which operate alongside the "formal, institutional or 'hard' territorially dominated spaces" (Allmendinger, Haughton \& Shepherd 2016: 41). One source of this fuzziness is Local Authorities' new 'Duty to Cooperate' created under the Act which is intended to help fill the strategic gap left between local and national government with the loss of RSSs (Allmendinger, Haughton \& Shepherd 2016:). The duty is important in linking local plans to flood and erosion management, binds a wide range of bodies and is designed to ensure that public bodies and statutory consultees involved in planning work together on issues that are of greater than local significance (Bide and Cranston 2014). This provides a statutory basis for cooperation and partnership working (Bide and Cranston 2014) but has led to somewhat ambiguous sub regions, a "space of planning smaller than a standard English region but larger than a typical local authority" Allmendinger, Haughton \& Shepherd 2016:39).

The outcome is "a multiscale risk governance network" (Begg, Walker and Kuhlicke 2015: 686) with a complex and changing set of bodies coming together around particular issues, each responsible for a different spatial area, potentially damaging the legitimacy of democratic processes and procedures (Allmendinger and Haughton, 2012). This complex arrangement exacerbates the already confusing and difficult to navigate relationship between policies for spatial planning, flood coastal risk management, and other water related issues (Bide and Cranston 2014) as Figure 1 below illustrates. It is in this complex, shifting, multi scale environment that actors must negotiate to reach decisions on whether to permit development in coastal areas designated at risk from flood or erosion. 


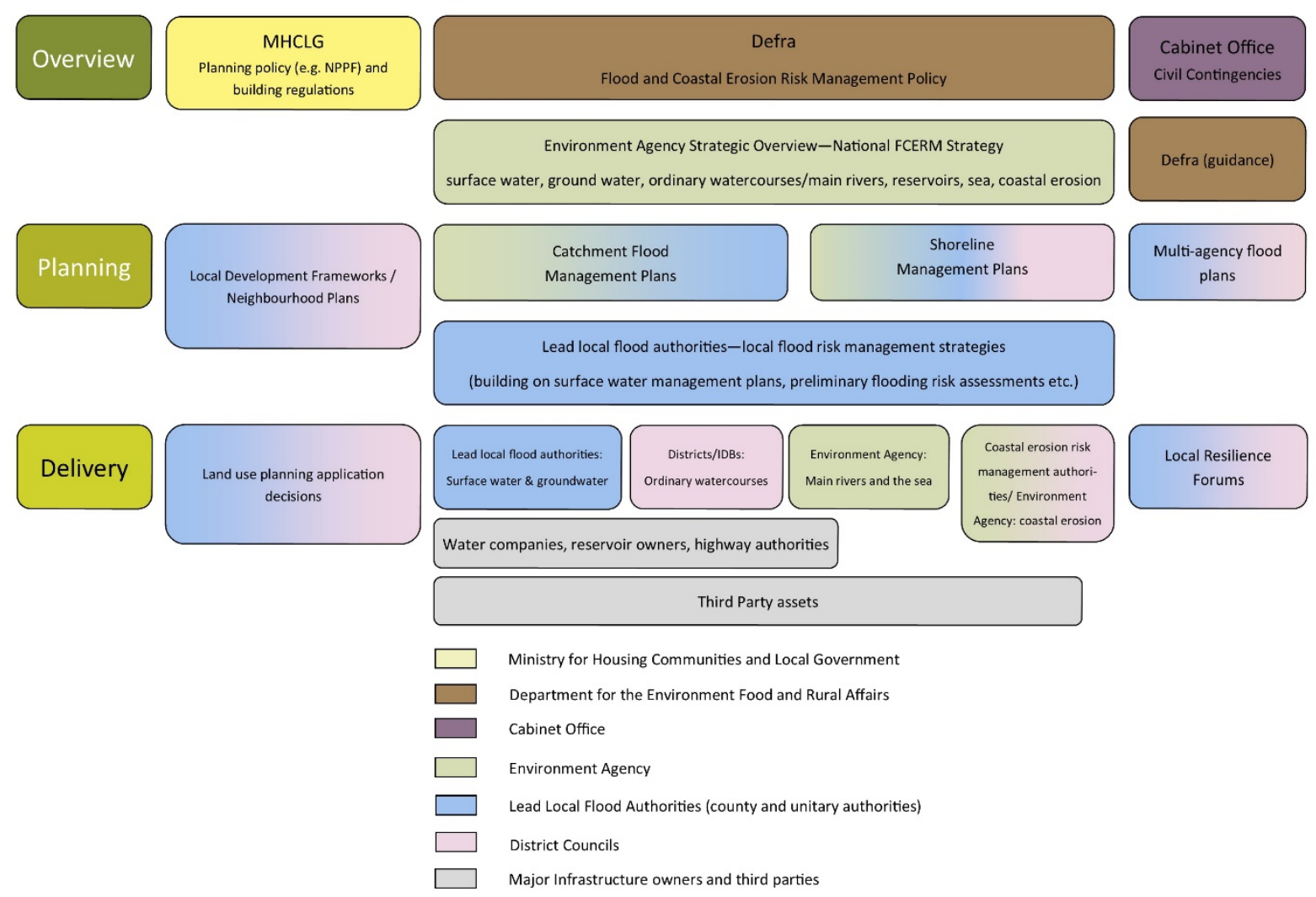

Fig 1. Flood and coastal erosion risk management - overview (Adapted and updated from EA 2011:4)

\section{Methods}

This paper is based on the English case studies from THESEUS (FP7 2009-2013); a European project exploring the potential for spatial planning to reduce future impacts through controlling the type and extent of property built in coastal flood or erosion risk areas. Qualitative interviews were carried out with informants in three coastal counties: South Devon (SD), North Norfolk (NN) and Lincolnshire (L) (see Fig. 2). Our sample frame targeted those with knowledge of the decision-making processes for allowing development in coastal areas at risk from flooding or erosion (see supplementary material). Thirty in-depth semi-structured interviews (Charmaz 2006) were conducted over $2 \frac{1}{2}$ years using discussion guides to ensure consistency across locations and between interviewers. The guides considered: understandings of the role of spatial planning; the international, national and regional context; local development planning; property rights and planning applications; public engagement; FCERM in relation to planning and evaluations of local spatial planning. Direct comparison is not possible given the varying nature of the case study areas. Rather, this exploratory qualitative research, uses constructivist grounded theory approaches (Charmaz 2006), with analysis aided by Nvivo software, to examine the challenges of taking flood and coastal erosion into consideration in planning decisions across these varying contexts during a time of considerable policy change (2011 -2013). It explores both formal and informal processes to understand from the actors' perspectives factors influencing the negotiation process. As objective results are not seen as possible in this approach, the findings are presented in the form of discussions based on analysis of the interviews. 


\subsection{Case study areas}

South Devon has one of the most diverse coastal settings in Europe. The largely rural area contains a World Heritage Coast site, Areas of Outstanding Natural Beauty (AONBs), nationally important estuarine habitat, salt marshes and managed sand dunes. The cities of Plymouth and Exeter are densely populated urbanised and industrial zones and there are many other smaller towns and villages. Plymouth also has a large naval base. The area experiences many and varied problems associated with storm events, flooding and coastal zone management; future sea level rise will lead to increased problems.

The North Norfolk District is a low-lying area whose rural landscapes are internationally recognised. Erosion was the main concern in the study area. The seven main towns and three large villages accommodate around half of the population. Both the population and the economy (dominated by tourism and the service sector) are set to grow significantly in the next two decades. Other challenges include a peripheral location, limited job opportunities, high house prices and an increasingly ageing population.

In Lincolnshire much of the coastal plain lies at or below sea level and is defended by $128 \mathrm{~km}$ of sea defences. A breach in the defences is predicted to lead to deep, rapid flooding and evacuation is a concern as are the large numbers living in static caravans. Lincolnshire is the largest single contributor to agricultural production in England. Coastal resorts such as Skegness and Mablethorpe also help generate income from tourism but deprivation is a concern.

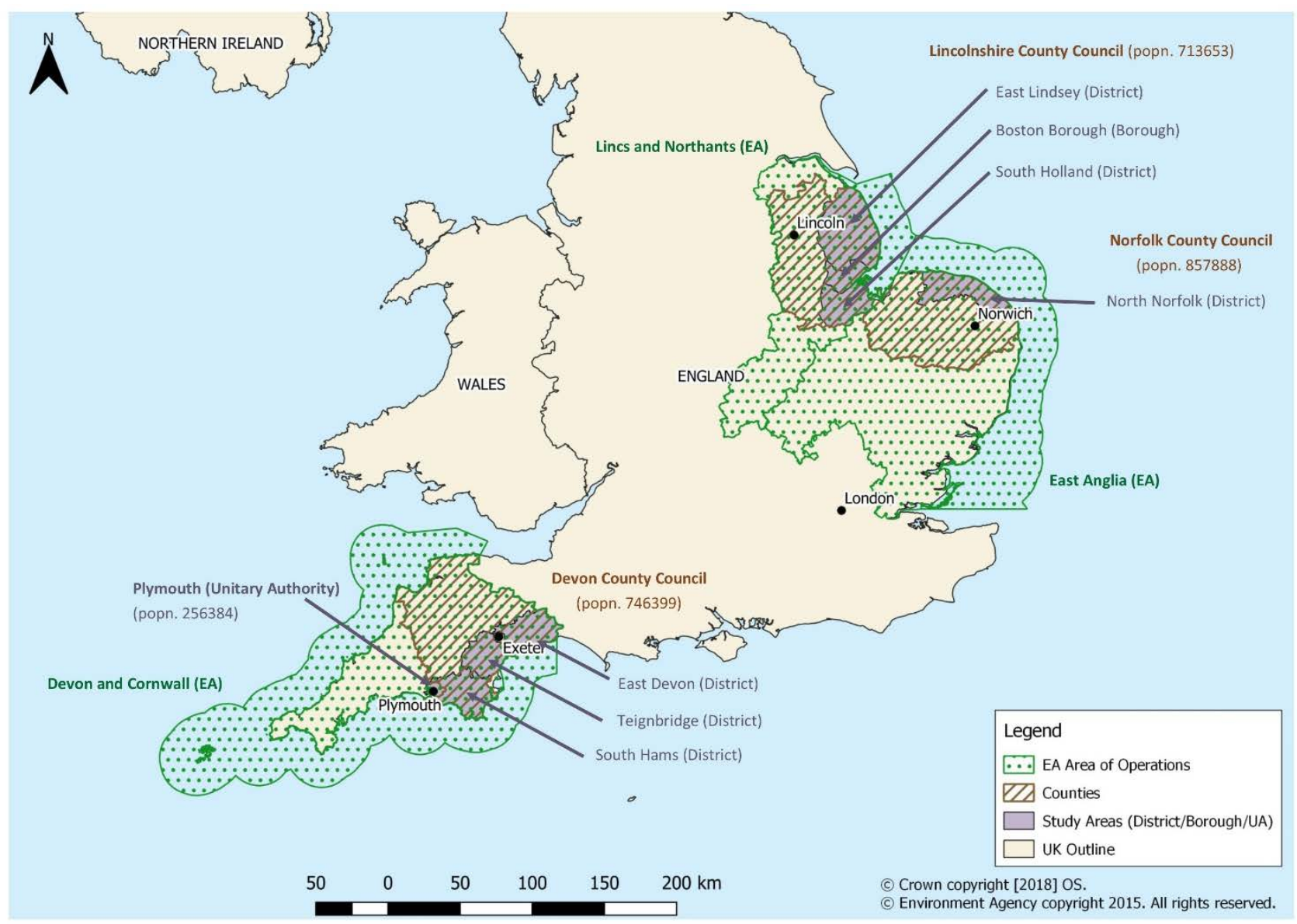

Fig. 2. Map showing case study locations and selected organisations' areas of responsibility

Population data from the 2011 census

EA boundaries are current versions (these have changed since research started) 


\section{Results and Discussion}

\subsection{Varying approaches to risk, the evidence base and its inherent uncertainty}

Planning decisions are supposed to be made on the basis of a robust evidence base (Bide and Cranston 2014) yet the evidence relating to flood and erosion risks, like all risk information, poses particular challenges in both collection and comprehension. Risk is a multi-dimensional concept and responses are influenced by numerous qualitative attributes, including familiarity with and knowledge of the particular risk and the communication of risk is mediated by the operation of complex institutional and social factors (DEFRA 2017). Yet, the negotiated approach to decision making rests on the risk dialogue model (Demeritt and Norbert 2014) where those involved should reach a shared agreement. The various stakeholders had differing degrees of familiarity and confidence with risk-based data, as well as different institutional concerns, and so took varying attitudes to its use. FCERM practitioners were most likely to be familiar with this type of evidence and comfortable using and interpreting it, whilst the planners had very varied degrees of experience. The complex and uncertain nature of the evidence base leaves it open to contestation on a number of aspects.

Some interviewees questioned underlying assumptions underpinning the data production, exploiting uncertainties within the data to frame the problem in a way that better suited their existing position. In one Lincolnshire LPA, the flood risk maps produced to guide planning decisions, assumed a breach of the existing sea defences which rendered much of the area unavailable for further development. A number of planners interviewed, who found the restrictions too onerous, disputed this approach arguing that the probability of occurrence should be taken into account because such a breach was unlikely. In contrast, those involved in FCERM argued this constituted the best available science and that a "precautionary approach" which makes plans on the basis of the consequences of a breach was the most appropriate. Even such basic issues as the level of map detail (coarseness) could lead to tensions. As one developer noted, the first thing that happens on receipt of the EA mapping data is that they "spend all their time proving that it's either wrong or totally inadequate for the job". Larger property developers have the time and resources to produce more detailed mapping and then to use this to argue their case for development in a restricted area through the planning process. This was felt by some, working within publicly funded government and local government departments with limited economic resources, to provide an unfair advantage. So rather than reaching a consensus on the risk, in this context actors took up different positions to champion.

The evolution of flood and erosion mapping, driven by scientific advances, policy requirements and subsequent investment, has increased the quality and quantity of data available but this can cause its own problems. For planners already grappling with the complexities of risk data, this added to their burden of work and could cause confusion. Similarly, it can cause problems when released into the public domain and the communication of risk information was a concern for local planning teams. Ironically, changes made to flood risk maps as a consequence of improvement in data production methods could lead to mistrust by the public who interpreted the change as a correction rather than an improvement. The release of new coastal erosion data was particularly contentious because impacts can include the total and uninsured loss of a dwelling. An EA officer in South Devon highlighted the difficulties in monitoring and predicting erosion, its episodic nature and the high levels of uncertainty within the data. Whilst a County Council Officer in South Devon feared that new erosion data would only be released in a "sanitised" form to avoid creating "riots in the streets". Yet he argued that the information should be made available as long as there was an appropriate explanation. This required a skill that some planning teams did not feel they possessed and so brought in from outside. Reaching a shared understanding of the risk data was also identified as an important issue in building effective relationships with the public.

Questions were raised by some regarding the level of 'acceptable risk' and who should be making this decision. The production of risk maps which restrict building in areas deemed above a certain threshold would suggest central government is making this decision. However, with development in these areas still being possible following negotiation, it is unclear who is making the final decision. Some planners argued that the public should not have risk levels imposed on them, rather they should be treated like "grown-ups" 
and allowed to choose for themselves. In Lincolnshire there was said to be an "appetite for risk" because of generations of exposure to flood risks. In contrast, EA interviewees highlighted the difficulties the public faced in understanding this information and the problems of persuading some residents that the risk exists at all, particularly where defences are provided. In North Norfolk with its erosion problems, dispute centred on whether to defend the coastline, with a move to managed retreat being unpopular. Without defences coastal erosion was seen not as a risk but as an unacceptable certainty. In South Devon interviewees felt that the key to residents accepting risk and the need for change was a measure of trust. They were able to develop this by bringing into the planning team a consultation expert who increased the effectiveness of their public engagement activities.

\subsection{Competing versions of local, organisational boundaries and strategic planning.}

This section highlights the difficulties encountered as individual actors experienced the demands of working within the complex and changing sets of bodies that must come together to make decisions at the coasts. In this multi-scale network (Begg, Walker and Kuhlicke 2015) competing versions of local led to tensions between actors trying to work together in a collaborative process. In this process of solving conflicting interests, interviewees tended to feel that one or more of the other groups held too much power. This contradictory set of views suggests the balance of power is not being dominated by one particular group but its distribution is unclear and difficult to predict.

Localism proposes that local actors are those best placed to find the solutions to local needs (Begg, Walker and Kuhlicke 2015) but fears that abolishing the Regional Spatial Strategies (RSSs) would lead to a vacuum for strategic planning (Communities and Local government 2011) seem to be justified. RSSs previously bridged the gap between planning issues determined by local policies and concerns, and those subject to nationally-determined policy aspirations, such as housing (Communities and Local Government 2011). As intended, local contexts and concerns are important in shaping local planning decisions, yet this can leave planners working within local authority boundaries with few options. In one Lincolnshire LPA the flood risk maps left almost no land available for new development. Under increasing pressure to find land for new businesses and housing (no longer allocated strategically under the RSS) in a relatively deprived area they found this "unrealistic". This put them at odds with EA staff, who may be locally based and work within geographic areas, but whose responsibility was to national guidelines to reduce the risks to people, properties and businesses from flooding and coastal erosion (EA 2018). Local planners were left trying to balance local and national needs within a relatively small geographic area, designated as almost entirely at flood risk. These tensions were reflected at the national level between the Department for Environment, Food and Rural Affairs (DEFRA) responsible for FCERM and the Department for Communities and Local Government (now MHCLG) responsible for housing as well as planning policy and regulations.

The introduction of partnership funding, where at least some of the money for flood defences must be raised locally, illustrates the complex interplay between local and national interests. A County Council Team Leader with responsibility for strategy and policy on flood risk management argued that the localisation of flood defence funding does not work for coastal flooding because many of the benefits provided are of national importance. "When you talk about coastal flooding, because of the importance of the agri-food industry, the large size of the visitor economy, the various national infrastructure, we think the coastal area actually provides national benefits, so to ask those specific communities to shoulder the burden of what's effectively a national defence system, we don't feel is right and we've said so to DEFRA on numerous occasions". In this relatively deprived area the local economy would struggle to meet the high costs involved in coastal defence schemes. So, the balance of costs and benefits between local and national can be hard to separate, particularly where it comes to coastal flooding, which in England tends to pose more risk to life than river flooding and be more expensive to defend against. Local scale debates are unlikely to be effective in resolving such issues. 
The need for a strategic approach at the coast, which connects local and national concerns, whilst recognising regional variation was articulated by an interviewee previously involved in managing the Regional Spatial Strategy (RSS) process. He stressed the need for a clear national strategy relating to flooding and planning which was able to take account of varied geographies and associated risks. He argued that "the British Government has no spatial policy" because "it acts as though geography doesn't exist", a problem attributed to a reduction in the scale of the state from the 1980s onwards and the rise of a neoliberal approach that leaves the private sector to resolve issues. The Regional Planning Body had previously attempted to fill this gap, developing a "vision for the coast" and creating a Coastal Strategy which attempted to connect policies operating at various scales. However, he felt this was hampered because they lacked control over the necessary investment to make the strategy deliverable and a lack of "alignment between the money, the investment and decisions about the use of land". Some of the documents produced as part of this strategy were still found useful and being used as evidence in planning decisions some years later. This demonstrates a demand for some form of strategic planning at the coast but no clear mechanism for its production.

In the absence of regional planning, strategic decisions about the coast must take place through both formal and semi-formal groupings of stakeholders who come together to solve particular problems under the Duty to Cooperate as part of the Localism Act 2011. Taking part in, understanding and managing such amorphous and disparate assemblages was often both time consuming and difficult for those interviewed. (Groups within the study areas can be seen in the supplementary material). There were also concerns that these did not include all the necessary stakeholders; in North Norfolk they used ad hoc approaches to solving the problems and to bring together the required range of expertise. Coastal areas have a particularly complex set of problems and an even wider range of organisations to bring together than those inland. In Plymouth (South Devon), the estuary, a large harbour and a military presence adds yet more competing organisational boundaries and additional stakeholders who must negotiate agreements. Much of planning is based on the premise of ownership, yet coastal areas can be uncertain in this respect. As a member of the South Devon \& Dorset Coastal Advisory Group explained "there are more areas on the coast which are held by public bodies or are common land or have historical rights attached to them. There are areas where authorities may have an influence depending on what state the tides at, whether it's a navigational issue or whether it's a land ownership issue, will depend on whether the tide's up or down". There are also overlapping areas of responsibility in marine and terrestrial plans. Therefore determining who should be involved, and reaching agreement between these disparate groups, is particularly problematic at the coast. There was agreement on the need for some strategic approach to what were cross boundary issues, but the scale and form proposed varied. So what we have is a complex and shifting mix of both formal and semi-formal groupings which are challenging to navigate by those on the inside and difficult to understand by those on the outside.

\subsection{Different planning timescales bring different problems into focus}

The purpose of the planning system as set out in the NPPF $(2012,2019)$ is to contribute to the achievement of sustainable development "meeting the needs of the present without compromising the ability of future generations to meet their own needs" (p2, p5). In doing so planners must balance economic, social and environmental objectives in a way that secure net gains across each of these three (NPPF 2019:5). In bringing together a range of stakeholders to agree on development decisions, conflicts between achieving the three objectives are highlighted and the factors influencing them are shown to operate at different timescales; a problem further confounded as organisations look ahead to different degrees. Similarly, in promoting resilience, competing versions may be put forward. To complicate matters, the further into the future plans are attempted, the less certainty there is generally in relation to the data.

Planning for the future may involve dealing with past decisions that no longer appear sound. North Norfolk has a number of properties in areas that are increasingly difficult to defend from coastal erosion. Yet, the planning process in general only deals with new development, therefore planners could not actively use spatial planning to adapt existing developments. As they moved from using coastal defences 'holding the 
line' towards some form of managed realignment, an increasing number of properties were at risk of falling into the sea. The threat of total destruction of residences, combined with the inability to insure against such losses, had rendered some properties worthless. Despite this there were no mechanisms within the standard planning system to resolve these problems. A DEFRA-funded Coastal Pathfinder Project (DEFRA 2012) was able to develop a methodology for the valuation and purchase of at-risk properties through a complicated range of different approaches, including relocating people and businesses. This would suggest that developing some means of revisiting past planning decisions would enable adaptation to changing conditions.

Disagreements occurred as organisations focused on different timescales which led them to prioritise different problems. Planners in Lincolnshire generally considered around 20 years hence as the maximum practical for a Local Plan. Similar timescales were used in the other locations, although North Norfolk planners considered longer periods in private discussions. In Lincolnshire, with its issues of poverty and associated social problems, there was a focus on the need for economic growth, achieved through allowing development. As one Lincolnshire planner stated "if we didn't put any development into this town then it would become more deprived, it would become less sustainable, we' $d$ have other social issues, it would just go backwards and that would be a disaster". Districts with a high proportion of their land at risk found this put them at odds with the EA whose focus was on longer term welfare in relation to the future impacts of flood and erosion, and their likely increase with climate change. Their concern, and indeed responsibility, was to prevent more people being put at risk and so they objected to proposed developments in at-risk areas. Similar tensions occurred where the EA suggested that there should be no new development in areas of Plymouth city centre and the spatial planning manager declared "that they were on a different planet to us". In contrast, another Lincolnshire district with a lower proportion of area at risk had a much better relationship with EA officers and much more sympathy for their point of view. So, we see clash of organisational emphasis exacerbated by a focus on different timescales. For some the more pressing and certain problems of social deprivation outweighed the longer term and uncertain risks associated with flooding and climate change. Although not framed in such terms this highlights competing resiliencies, with planners' effectively prioritising economic and associated social resilience operating in the short to medium term.

Shoreline Management Plans (SMPs) which describe how the shoreline is to be managed to address flood and/or erosion are the only area of local planning to formally consider longer timescales and these look 20, 50 and 100 years hence (See Fig. 1). These SMPs are not statutory documents but guide how funding strategies and maintenance strategies might be fixed for certain periods of time. The difficulty in integrating the demands of SMPs with LPs was highlighted by a forward planning manager in Lincolnshire: "because those plans [SMPs] look at things like sea level rise over the next 100 years ... and local plans obviously have a more immediate need to meet". He felt such long timescales were impractical for other areas of planning; "really it's the only part of local planning that looks that far ahead ... if we did similar exercises for what changes to transport might occur, or health, or other things, then we would probably never get anything done". The value of looking forward as far as 50 and 100 years was questioned by a joint planning unit manager "because the science is still to be fully understood" and so we should be "dealing with what you understand and not sort of guessing what might be suitable in the longer term". The planning system has to balance a wide variety of competing needs across medium and longer terms. Each tends to highlight different concerns and there is no simple resolution. It is perhaps not surprising that the longer term, less pressing and less certain problems of flood and erosion may become a lower priority in some contexts.

\section{Conclusions}

In the interface between SP and FCERM for development decisions two already complex systems are brought together. As the links between FCERM and planning are still being developed and are often made through multiple routes and around various organisations and projects, some of which are formed for a limited time only, the result is complex networks of connections at a range of sub-national scales. Different organisational 
concerns operate across different scales and boundaries under the banner of 'local' and planning discussions are left to resolve the tensions highlighted. In this collaborative process stakeholder relationships are shaped by interactions between boundaries, risk mapping and local priorities. The Duty to Cooperate intensifies complexity and brings together disparate groups to solve difficult decisions. This method of filling the strategic gap left by the loss of regional planning was found by some to be inadequate, and it left local planning discussions to solve issues such as housing, where targets were set by national policies, or to resolve national government tensions between housing need and reducing exposure of future populations to flood and erosion.

Such problems are intensified because of the difficulties in understanding and communicating risk data and its inherent uncertainties. Participants in the collaborative process bring very different experiences of such data and different planning concerns may highlight and prioritise risks other than flood or erosion. Uncertainties within the data allow the participants to take up different perspectives to support their existing positions. This uncertainty tends to increase the further into the future is considered, and this hampers consideration of the longer-term risks of flood and erosion influenced by climate change. As the stakeholders involved adopt different planning timescales, different risks come into view, and which will 'win' in this deliberative process is very context dependent and difficult to predict. Arguably this is the desired outcome, finding local solutions for local problems. However, transparency and accountability are difficult under this shifting, multi scale system, where only some actors are democratically accountable. This raises the question of whether this form of localism will prove an effective and fair way to resolve difficult issues such as the pressing national shortage of housing or deciding on what is an acceptable level of flood or erosion risk for the population.

\section{Recommendations}

The following are proposed as practical suggestions to alleviate some of the existing problems.

- Informal groupings of stakeholders need to consider how to make their relationships more visible and so more accountable.

- Stakeholders should explicitly recognise their different geographic areas of responsibility, organisational scope and planning horizons when embarking on collaborations.

- In dialogues concerning risk, those less familiar with this type of data and its production need support

- Planning teams would benefit from the inclusion of those with expertise in risk communication

- Stronger national guidance on acceptable levels of risk would reduce friction in local decisions

- Planning issues of national concern such as housing require stronger strategic guidance

\section{Acknowledgements}

This work was supported by the European Commission through the Grant 244104, THESEUS "Innovative technologies for safer European coastal areas", www.theseusproject.eu, 2009-2013. We would also like to thank Joshua Coates for assistance in producing the maps and diagrams used in this article. Finally we would like to thank the two anonymous reviewers for their constructive comments. 


\section{References}

Albrechts, L., 2004. Strategic (spatial) planning reexamined. Environment and Planning B: Planning and Design, 31(5), pp.743-758. Available at: http://www.envplan.com/abstract.cgi?id=b3065 [Accessed May 26, 2014].

Aldunce, P., Beilin, R., Handmer, J. \& Mark Howden (2016) Stakeholder participation in building resilience to disasters in a changing climate, Environmental Hazards, 15:1, 58-73, DOI:

10.1080/17477891.2015.1134427

Allmendinger, P. \& Haughton, G., 2007. The fluid scales and scope of UK spatial planning. Environment and Planning A, 39(6), pp.1478-1496.

Allmendinger, P. \& Haughton, G., 2012. Post-political spatial planning in England: A crisis of consensus? Transactions of the Institute of British Geographers, 37(1), pp.89-103.

Allmendinger, P., Haughton, G. \& Shepherd, E., 2016. Where is planning to be found? Material practices and the multiple spaces of planning. Environment and Planning C: Government and Policy, 34(1), pp.38-51.

Begg, C., Walker, G. \& Kuhlicke, C., 2015. Localism and flood risk management in England: The creation of new inequalities? Environment and Planning C: Government and Policy, 33(4), pp.685-702.

Bide P and Cranston G, 2014. Planning Advice for Integrated Water Management, Available at: http://www.ciwem.org/wpcontent/uploads/2016/02/Natural_Capital_Leaders_Platform_Water_Planning_Advice_Note_June_2014.p df.

Challies, E., Newig, J., Thaler, T., Kochskämper,. \& Levin-Keitel, M. 2016. Participatory and collaborative governance for sustainable flood risk management: An emerging research agenda. Environmental Science \& Policy, 55, Part 2(January), pp.275-280. Available at:

http://www.sciencedirect.com/science/article/pii/S1462901115001616.

Charmaz, K., 2006 Constructing Grounded Theory: A Practical Guide through Qualitative Analysis London: Sage

Communities and Local Government Committee 2011 - Second Report. Abolition of Regional Spatial Strategies: a planning vacuum? Available at: https://publications.parliament.uk/pa/cm201011/cmselect/cmcomloc/517/517.pdf

DCLG 2012. National Planning Policy Framework, Available at:

http://webarchive.nationalarchives.gov.uk/20180608095821/https://www.gov.uk/government/publication s/national-planning-policy-framework

DCLG 2011 A Plain English Guide to the Localism Bill. Available at: https://assets.publishing.service.gov.uk/government/uploads/system/uploads/attachment_data/file/5959/ 1896534.pdf

DEFRA 2017 Defra Science Advisory Council - Social Science Expert Group (SSEG) Task Group Report: Communicating Risk (November 2017). Available at: https://assets.publishing.service.gov.uk/government/uploads/system/uploads/attachment_data/file/6848 54/sac-sseg-communicating-risk-2017.pdf (accessed 12/6/19).

DEFRA, 2012 Coastal Change Pathfinder Review. Final Report. DEFRA, London

Demeritt, D. \& Nobert, S., 2014. Models of best practice in flood risk communication and management. Environmental Hazards, 13(4), pp.313-328. Available at: http://www.tandfonline.com/doi/abs/10.1080/17477891.2014.924897\#.VRPRTJOsVy4. 
EA 2018. Managing flood and coastal erosion risks in England: 1 April 2011 to 31 March 2017, Available at: www.gov.uk/government/publications/flood-and-coastal-risk-management-national-report (accessed $16 / 8 / 18)$

Faulkner, H., Parker, D., Green, C., Beven, K., 2007. Developing a translational discourse to communicate uncertainty in flood risk between science and the practitioner. AMBIO: J. Hum. Environ. 36 (8), 692-704. https://doi.org/10.1579/0044-7447\%282007\%2936\%5B692\%3ADATDTC\%5D2.0.CO\%3B2.

Green, C., 2014. Competent authorities for the flood risk management plan - reflections on flood and spatial planning in England. Journal of Flood Risk Management, p.n/a-n/a. Available at: http://doi.wiley.com/10.1111/jfr3.12097.

Kuklicke, C. \& Demeritt, D., 2016. Adaptive and risk-based approaches to climate change and the management of uncertainty and institutional risk: The case of future flooding in England. Global Environmental Change, 37, pp.56-68. Available at: http://dx.doi.org/10.1016/j.gloenvcha.2016.01.007.

Leiss, W., 1996. Three Phases in the Evolution of Risk Communication Practice. Annals of the American Academy of Political and Social Science, 545(August), pp.85-94. Available at:

http://www.jstor.org.ezproxy.library.ubc.ca/stable/1047895\%5Cnhttp://www.jstor.org.ezproxy.library.ubc. ca/stable/pdfplus/1047895.pdf?acceptTC=true.

Localism Act 2011, Part 6, Available at http://www.legislation.gov.uk/ukpga/2011/20/contents/enacted (accessed 13/6/10).

MHCLG, 2019. National Planning Policy Framework, Available at:

https://assets.publishing.service.gov.uk/government/uploads/system/uploads/attachment_data/file/7797 64/NPPF_Feb_2019_web.pdf

Pardoe, J., Penning-Rowsell, E. \& Tunstall, S., 2011. Floodplain conflicts: Regulation and negotiation. Natural Hazards and Earth System Science, 11(10), pp.2889-2902.

Porter, J. \& Demeritt, D., 2012. Flood-risk management, mapping, and planning: The institutional politics of decision support in England. Environment and Planning A, 44(10), pp.2359-2378.

Smith, L. \& Priestly, S., 2016. Planning and Flood Risk. Briefing paper No 0751729 February 2016, (07517). Available at: http://researchbriefings.files.parliament.uk/documents/CBP-7517/CBP-7517.pdf.

Tanner, T., Bahadur, A., Moench, M., 2017. Challenges for Resilience Policy and Practice. Overseas Development Institute, London. Available at https://www.odi.org/sites/odi.org.uk/files/resourcedocuments/11733.pdf.

Thaler, T. and Levin-Keitel, M. (2016) 'Multi-level stakeholder engagement in flood risk management-A question of roles and power: Lessons from England', Environmental Science and Policy. Elsevier Ltd, 55, pp. 292-301. doi: 10.1016/j.envsci.2015.04.007.

Walker, J. \& Cooper, M., 2011. Genealogies of resilience. Security Dialogue, 42(2), pp.143-160. Available at: http://journals.sagepub.com/doi/10.1177/0967010611399616.

Weichselgartner, J. \& Kelman, I., 2014. Geographies of resilience: Challenges and opportunities of a descriptive concept. Progress in Human Geography. Available at:

http://phg.sagepub.com/cgi/doi/10.1177/0309132513518834 [Accessed May 25, 2014].

Welsh, M., 2013. Resilience and responsibility: Governing uncertainty in a complex world. Geographical Journal, 180(1), pp.15-26.

White, I. \& O' Hare, P., 2014. From rhetoric to reality: Which resilience, why resilience, and whose resilience in spatial planning? Environment and Planning C: Government and Policy, 32(5), pp.934-950. 